\title{
Interleukin-16 Polymorphism Is Associated with an Increased Risk of Ischemic Stroke
}

\author{
Xiao-li Liu, ${ }^{1}$ Jian-zong Du, ${ }^{2}$ Yu-miao Zhou, ${ }^{1}$ Qin-fen Shu, ${ }^{1}$ and Ya-guo Li ${ }^{1}$ \\ ${ }^{1}$ Department of Neurology, Zhejiang Hospital, Hangzhou, Zhejiang 310013, China \\ ${ }^{2}$ Department of Respiratory, Zhejiang Hospital, Hangzhou, Zhejiang 310013, China
}

Correspondence should be addressed to Ya-guo Li; yaguoli@163.com

Received 24 July 2013; Accepted 22 September 2013

Academic Editor: Dianne Cooper

Copyright (c) 2013 Xiao-li Liu et al. This is an open access article distributed under the Creative Commons Attribution License, which permits unrestricted use, distribution, and reproduction in any medium, provided the original work is properly cited.

Clinical and experimental data have demonstrated that inflammation plays fundamental roles in the pathogenesis of ischemic stroke. Interleukin-16 (IL-16) is identified as a proinflammatory cytokine that is a key element in the ischemic cascade after cerebral ischemia. We aimed to examine the relationship between the $I L-16$ polymorphisms and the risk of ischemic stroke in a Chinese population. A total of 198 patients with ischemic stroke and 236 controls were genotyped using polymerase chain reactionrestriction fragment length polymorphism (PCR-RFLP) and DNA sequencing method. We found that the rs11556218TG genotype and $\mathrm{G}$ allele of $I L-16$ were associated with significantly increased risks of ischemic stroke (TG versus TT, adjusted OR $=1.88$; 95\% CI, 1.15-3.07; G versus T, adjusted OR $=1.54$; 95\% CI, 1.05-2.27, resp.). However, there were no significant differences in the genotype and allele frequencies of $I L-16$ rs4778889 T/C and rs4072111 C/T polymorphisms between the two groups, even after stratification analyses by age, gender, and the presence or absence of hypertension, diabetes mellitus, hypercholesterolemia, and hypertriglyceridemia. These findings indicate that the $I L-16$ polymorphism may be related to the etiology of ischemic stroke in the Chinese population.

\section{Introduction}

Stroke is a complex multifactorial disorder and a leading cause of mortality and morbidity worldwide. Approximately, $70-80 \%$ of all cases are ischemic stroke (IS) [1]. Growing evidence has shown that inflammation appears to play crucial roles in the pathogenesis of IS through the promotion of atherosclerosis. Clinically, the incidence and outcome of IS are influenced by systemic inflammatory processes, and stroke patients with systemic inflammation portend poorer outcomes [2-4]. Experimentally, focal ischemic injury with acute and chronic inflammation induces production of proinflammatory mediators and recruitment of inflammatory cells, including neutrophils, $\mathrm{T}$ cells, and monocyte/macrophages [5-7]. In addition to some known risk factors, such as inflammation, advanced age, hypertension, and diabetes, genetic variants have been reported to contribute to the development of IS [8-10]. Identification of susceptibility genes is of great value to clarify the aetiology and improve prognostication, therapy, and prevention.
Interleukin-16 (IL-16) was originally discovered as lymphocyte chemoattractant factor in 1982 [11]. Subsequently, it was identified as a proinflammatory cytokine that is a $67 \mathrm{kD}$ precursor protein consisting of 631 amino acids. The gene encoding IL-16 is located on chromosome $15 \mathrm{q} 26.3$ in humans [12-14]. IL-16 is produced by activated CD8positive (CD8+) T cells [15] and activates CD4+ T cells, monocytes, macrophages, and dendritic cells by binding to theCD4 molecular $[16,17]$. In addition to the activation of CD4+ T cells, IL-16 can promote the secretion of inflammatory cytokines such as tumour necrosis factor (TNF) $\alpha$, interleukin-1 $\beta$, and interleukin-6 (IL-6) [18]. All of these cytokines are key elements in the ischemic cascade after cerebral ischemia [19-22].

In 2000, Nakayama and colleagues found a -295T-toC polymorphism in the promoter region of $I L-16$, which is related to different levels of gene expression [23]. The polymorphism was reported to be associated with a series of inflammatory or autoimmune diseases, including Crohn's disease [24], allergic contact dermatitis [25], endometriosis 
TABLE 1: Characteristics of study subjects.

\begin{tabular}{lccc}
\hline Variables & IS $(n=198)$ & Controls $(n=236)$ & $P$ value \\
\hline Age (years, mean \pm SD) & $57.2 \pm 11.8$ & $55.4 \pm 11.7$ & 0.12 \\
Gender (\%) & & & \\
$\quad$ Male & $122(61.6)$ & $155(65.7)$ & 0.38 \\
$\quad$ Female & $76(38.4)$ & $81(34.3)$ & \\
Hypertension (\%) & $119(60.1)$ & $22(9.3)$ & $<0.001$ \\
Diabetes mellitus (\%) & $40(20.2)$ & $8(3.4)$ & $<0.001$ \\
Hypercholesterolemia (\%) & $27(13.6)$ & $26(11.0)$ & 0.41 \\
Hypertriglyceridemia (\%) & $56(28.3)$ & $61(25.8)$ & 0.57 \\
\hline
\end{tabular}

IS: ischemia stroke; SD: standard deviation.

[26], asthma [27], Graves' disease [28], and systemic lupus erythematosus (SLE) [29]. Recently, another two functional polymorphisms (i.e., rs11556218 and rs4072111) were identified to be associated with SLE [29] and coronary artery disease (CAD) [30, 31]. To date, no data exist regarding the contribution of the $I L-16$ polymorphisms to IS. In this study, we aimed to assess the prevalence of the $I L-16$ polymorphisms in IS.

\section{Materials and Methods}

2.1. Study Population. The study was approved by the Zhejiang Hospital Institutional Review Board for Human Subjects Research, and written informed consent was obtained from all individuals. The study population comprised 434 unrelated Chinese subjects who visited the Zhejiang Hospital between March 2010 and September 2012. Among them, 198 were patients with IS (122 men and 76 women) and 236 were healthy controls ( 155 men and 81 women). IS was determined by the presence of a focal or global neurological deficit with symptoms and signs lasting more than $24 \mathrm{~h}$. Computed tomography and/or magnetic resonance image scanning of the brain was used to ascertain the diagnosis of IS. The subgroups of IS were classified using the TOAST criteria [32]. Hypertension was defined as having a systolic blood pressure $\geq 140 \mathrm{mmHg}$ and/or a diastolic blood pressure $\geq 90 \mathrm{mmHg}$. Diabetes mellitus was diagnosed if the fasting plasma glucose level $\geq 7.0 \mathrm{mmol} / 1$ or the plasma glucose $\geq 11.1 \mathrm{mmol} / 12$ hours after a $75 \mathrm{~g}$ oral glucose tolerance test. Hypercholesterolemia was determined by a fasting serum cholesterol level $>6.2 \mathrm{mmol} / \mathrm{L}$, and hypertriglyceridemia was determined by a fasting serum triglyceride level $>2.3 \mathrm{mmol} / \mathrm{L}$ [33]. We used hospital-based controls that were age, gender, and ethnicity matched, without a history of IS.

2.2. Genotyping. Genomic DNA was isolated from peripheral blood leukocytes by the salting-out method [34]. IL-16 polymorphisms were genotyped by performing polymerase chain reaction-restriction fragment length polymorphism (PCR-RFLP) assay. Primer sequences and reaction conditions were used as described previously [35]. For quality control, randomly selected PCR products were examined by DNA sequencing, and the results were $100 \%$ concordant.
TABLE 2: Genotype and allele distributions of the $I L-16$ gene polymorphisms in IS cases and controls.

\begin{tabular}{|c|c|c|c|c|}
\hline & $\begin{array}{c}\text { IS cases } \\
n(\%)\end{array}$ & $\begin{array}{c}\text { Controls } \\
n(\%)\end{array}$ & $\begin{array}{c}\text { Adjusted } \\
\text { OR }(95 \% \text { CI })\end{array}$ & $P$ value \\
\hline \multicolumn{5}{|c|}{ rs4778889 T/C } \\
\hline \multicolumn{5}{|c|}{ Genotypes } \\
\hline TT & $124(62.6)$ & $138(58.5)$ & 1.00 & \\
\hline TC & $66(33.3)$ & $88(37.3)$ & $0.56(0.16-1.98)$ & 0.36 \\
\hline $\mathrm{CC}$ & $8(4.0)$ & $10(4.2)$ & $0.94(0.57-1.56)$ & 0.82 \\
\hline \multicolumn{5}{|l|}{ Alleles } \\
\hline $\mathrm{T}$ & $314(79.3)$ & $364(77.1)$ & 1.00 & \\
\hline $\mathrm{C}$ & $82(20.7)$ & $108(22.9)$ & $0.93(0.61-1.40)$ & 0.72 \\
\hline \multicolumn{5}{|c|}{ rs11556218 T/G } \\
\hline \multicolumn{5}{|c|}{ Genotypes } \\
\hline TT & $88(44.4)$ & $136(57.6)$ & 1.00 & \\
\hline TG & $102(51.5)$ & $94(39.8)$ & $1.88(1.15-3.07)$ & 0.01 \\
\hline GG & $8(4.0)$ & $6(2.5)$ & $2.38(0.63-9.05)$ & 0.20 \\
\hline \multicolumn{5}{|l|}{ Alleles } \\
\hline $\mathrm{T}$ & $278(70.2)$ & $366(77.5)$ & 1.00 & \\
\hline G & $118(29.8)$ & $106(22.5)$ & $1.54(1.05-2.27)$ & 0.03 \\
\hline \multicolumn{5}{|c|}{ rs4072111 C/T } \\
\hline \multicolumn{5}{|c|}{ Genotypes } \\
\hline $\mathrm{CC}$ & $125(63.1)$ & $141(59.7)$ & 1.00 & \\
\hline CT & $63(31.8)$ & $85(36.0)$ & $0.62(0.37-1.04)$ & 0.07 \\
\hline TT & $10(5.1)$ & $10(4.2)$ & $1.38(0.48-3.97)$ & 0.55 \\
\hline \multicolumn{5}{|l|}{ Alleles } \\
\hline C & $313(79.0)$ & $367(77.8)$ & 1.00 & \\
\hline $\mathrm{T}$ & $83(21.0)$ & $105(22.2)$ & $0.76(0.49-1.16)$ & 0.20 \\
\hline
\end{tabular}

OR was adjusted for age, gender, hypertension, diabetes mellitus, hypercholesterolemia, and hypertriglyceridemia by binary logistic regression analysis.

2.3. Statistical Analysis. All data were analyzed using the SPSS software (version 19.0, SPSS Inc., Chicago, IL). To detect the agreement of the $I L-16$ genotype frequency, Hardy-Weinberg equilibrium was tested with a goodness-of-fit $\chi^{2}$ test. Demographic and clinical data between cases and controls were compared using the $\chi^{2}$ test for dichotomous covariates and unpaired Student's $t$-test for continuous covariates. A binary logistic regression analysis was used to compute adjusted odds ratio (OR) and 95\% confidence intervals (CI) for evaluating the association of the $I L-16$ polymorphisms with IS. The criterion of statistical significance was set at $P<0.05$.

\section{Results}

The characteristics of cases and controls are summarized in Table 1. The genotype and allele frequencies of the rs4778889 $\mathrm{T} / \mathrm{C}$, rs $11556218 \mathrm{~T} / \mathrm{G}$, and rs4072111 C/T polymorphisms in $I L-16$ gene are summarized in Table 2 . The genotype distributions of the three polymorphisms in controls were consistent with the Hardy-Weinberg equilibrium. The genotype frequencies of the rs11556218 T/G polymorphism were 
significantly different between cases and controls. The TG genotype of the rs11556218 T/G polymorphism was associated with a significantly increased risk of IS compared with the TT genotype (adjusted OR $=1.88 ; 95 \% \mathrm{CI}, 1.15-3.07$ ). Similarly, the $\mathrm{G}$ allele of the rs $11556218 \mathrm{~T} / \mathrm{G}$ polymorphism was associated with a significantly increased risk of IS compared with the $\mathrm{T}$ allele (adjusted $\mathrm{OR}=1.54 ; 95 \% \mathrm{CI}$, 1.05-2.27). However, there were no significant differences in the genotype and allele frequencies of $I L-16$ rs4778889 $\mathrm{T} / \mathrm{C}$ and rs4072111 $\mathrm{C} / \mathrm{T}$ polymorphisms between the two groups, even after stratification analyses by age, gender, and the presence or absence of hypertension, diabetes mellitus, hypercholesterolemia, and hypertriglyceridemia.

\section{Discussion}

Clinical and experimental data have demonstrated that inflammation plays fundamental roles in the pathogenesis of IS [2-7]. An increased level of $I L-16$ mRNA and protein was observed in patients with inflammatory or autoimmune diseases, and the high expression of IL-16 mRNA correlated with increased numbers of CD4+ cells in acute skin lesions $[36,37]$. Ischemic stroke patients had a high risk for systemic infections, and anti-inflammatory agents may be a promising approach to treating IS $[6,38,39]$.

Based on the key roles of $I L-16$ in inflammatory disorders, the association between $I L-16$ polymorphism and the risk of inflammatory diseases has attracted widespread attention over the past decades. Some authors reported that the rs4778889 polymorphism was associated with increased risks of developing allergic contact dermatitis [25], Graves' disease [28], SLE [29], and endometriosis [26]. In contrast, some researchers reported that the rs4778889 polymorphism was not related to the risk of periodontitis [40] and CAD [30, 31]. In this study, we failed to find any association between the rs4778889 polymorphism and the risk of IS. These findings suggest that the rs 4778889 polymorphism may have different roles in different diseases.

Recently, another two nonsynonymous polymorphisms were identified (rs11556218 T/G and rs4072111 C/T). The two polymorphisms were reported to be associated with increased risks of developing SLE [29] and CAD [30, 31]. In conformity with the results, we found that the frequency of the rs11556218TG genotype in IS group was significantly higher than that in the control group, indicating that the $I L$ 16 rs11556218 polymorphism may be used as a genetic marker for IS.

Although the mechanism of IL-16 as an inflammatory mediator is still not fully known, there is evidence that IL16 participates in the inflammatory disorder through the activation of $\mathrm{T}$ lymphocytes and the secretion of inflammatory cytokines [41, 42]. In the early stages following an ischemic stroke, $\mathrm{T}$ lymphocytes were activated, released reactive oxygen species, and finally contributed to brain injury. In the later stages, $\mathrm{T}$ lymphocytes can regulate the repair and regeneration of the brain [41]. Depletion of $\mathrm{T}$ lymphocytes can reduce stroke size during the acute phase of ischemia, and the protective effect against stroke lasted in the later stages of infarct development [42]. This evidence may explain the possible role of $I L-16$ gene polymorphism in IS.

In conclusion, this study provides the first evidence for associations of $I L-16$ gene polymorphisms with risk of IS in the Chinese population. The TG genotype and G allele of the rs11556218 polymorphism may have a promoting effect on IS. However, further studies are warranted in order to shed more light on the molecular mechanism.

\section{Authors' Contribution}

Xiao-li Liu and Jian-zong Du contributed equally to this work.

\section{Acknowledgment}

This work was supported by the Science and Technology Plan Projects of Zhejiang Province (no. 2010C33002).

\section{References}

[1] R. Bonita, S. Mendis, T. Truelsen, J. Bogousslavsky, J. Toole, and F. Yatsu, "The global stroke initiative," Lancet Neurology, vol. 3, no. 7, pp. 391-393, 2004.

[2] T. A. Baird, M. W. Parsons, P. A. Barber et al., "The influence of diabetes mellitus and hyperglycaemia on stroke incidence and outcome," Journal of Clinical Neuroscience, vol. 9, no. 6, pp. 618626, 2002.

[3] M. S. V. Elkind, J. Cheng, T. Rundek, B. Boden-Albala, and R. L. Sacco, "Leukocyte count predicts outcome after ischemic stroke: the Northern Manhattan Stroke Study," Journal of Stroke and Cerebrovascular Diseases, vol. 13, no. 5, pp. 220-227, 2004.

[4] B. W. McColl, S. M. Allan, and N. J. Rothwell, "Systemic infection, inflammation and acute ischemic stroke," Neuroscience, vol. 158, no. 3, pp. 1049-1061, 2009.

[5] R. Jin, G. Yang, and G. Li, "Inflammatory mechanisms in ischemic stroke: role of inflammatory cells," Journal of Leukocyte Biology, vol. 87, no. 5, pp. 779-789, 2010.

[6] X. Wang, "Investigational anti-inflammatory agents for the treatment of ischaemic brain injury," Expert Opinion on Investigational Drugs, vol. 14, no. 4, pp. 393-409, 2005.

[7] G. Yilmaz and D. N. Granger, "Cell adhesion molecules and ischemic stroke," Neurological Research, vol. 30, no. 8, pp. 783793, 2008.

[8] P. Sharma, "Genes for ischaemic stroke: strategies for their detection," Journal of Hypertension, vol. 14, no. 3, pp. 277-285, 1996.

[9] C. Xu, F. Wang, B. Wang et al., "Minor allele C of chromosome 1p32 single nucleotide polymorphism rs11206510 confers risk of ischemic stroke in the chinese han population," Stroke, vol. 41, no. 8, pp. 1587-1592, 2010.

[10] Z. Zhang, G. Xu, D. Liu, X. Fan, W. Zhu, and X. Liu, "Angiotensin-converting enzyme insertion/deletion polymorphism contributes to ischemic stroke risk: a meta-analysis of 50 case-control studies," PLoS One, vol. 7, no. 10, Article ID e46495, 2012.

[11] D. M. Center and W. Cruikshank, "Modulation of lymphocyte migration by human lymphokines. I. Identification and characterization of chemoattractant activity for lymphocytes from 
mitogen-stimulated mononuclear cells," Journal of Immunology, vol. 128, no. 6, pp. 2563-2568, 1982.

[12] M. Baier, N. Bannert, A. Werner, K. Lang, and R. Kurth, "Molecular cloning, sequence, expression, and processing of the interleukin 16 precursor," Proceedings of the National Academy of Sciences of the United States of America, vol. 94, no. 10, pp. 5273-5277, 1997.

[13] H. L. Drwinga, L. H. Toji, C. H. Kim, A. E. Greene, and R. A. Mulivor, "NIGMS human/rodent somatic cell hybrid mapping panels 1 and 2," Genomics, vol. 16, no. 2, pp. 311-314, 1993.

[14] Y. Zhang, D. M. Center, D. M. H. Wu et al., "Processing and activation of pro-interleukin-16 by caspase-3," Journal of Biological Chemistry, vol. 273, no. 2, pp. 1144-1149, 1998.

[15] S. Laberge, W. W. Cruikshank, H. Kornfeld, and D. M. Center, "Histamine-induced secretion of lymphocyte chemoattractant factor from CD8+ T cells is independent of transcription and translation: evidence for constitutive protein synthesis and storage," Journal of Immunology, vol. 155, no. 6, pp. 2902-2910, 1995.

[16] D. M. Center, H. Kornfeld, and W. W. Cruikshank, "Interleukin 16 and its function as a CD4 ligand," Immunology Today, vol. 17, no. 10 , pp. 476-481, 1996.

[17] W. W. Cruikshank, D. M. Center, N. Nisar et al., "Molecular and functional analysis of a lymphocyte chemoattractant factor: association of biologic function with CD4 expression," Proceedings of the National Academy of Sciences of the United States of America, vol. 91, no. 11, pp. 5109-5113, 1994.

[18] N. L. Mathy, W. Scheuer, M. Lanzendörfer et al., "Interleukin-16 stimulates the expression and production of pro-inflammatory cytokines by human monocytes," Immunology, vol. 100, no. 1, pp. 63-69, 2000.

[19] A.-G. Ceulemans, T. Zgavc, R. Kooijman, S. Hachimi-Idrissi, S. Sarre, and Y. Michotte, "The dual role of the neuroinflammatory response after ischemic stroke: modulatory effects of hypothermia," Journal of Neuroinflammation, vol. 7, article 74, 2010.

[20] C. E. Downes and P. J. Crack, "Neural injury following stroke: are Toll-like receptors the link between the immune system and the CNS?" British Journal of Pharmacology, vol. 160, no. 8, pp. 1872-1888, 2010.

[21] K. L. Lambertsen, K. Biber, and B. Finsen, "Inflammatory cytokines in experimental and human stroke," Journal of Cerebral Blood Flow \& Metabolism, vol. 32, no. 9, pp. 1677-1698, 2012.

[22] A. Tuttolomondo, D. di Raimondo, R. Pecoraro et al., "Inflammation in ischemic stroke subtypes," Current Pharmaceutical Design, vol. 18, no. 28, pp. 4289-4310, 2012.

[23] E. E. Nakayama, C. Wasi, A. Ajisawa, A. Iwamoto, and T. Shioda, "A new polymorphism in the promoter region of the human interleukin-16 (IL-16) gene," Genes and Immunity, vol. 1, no. 4, pp. 293-294, 2000.

[24] J. Glas, H. P. Török, H. Unterhuber, M. Radlmayr, and C. Folwaczny, "The -295T-to-C promoter polymorphism of the IL16 gene is associated with Crohn's disease," Clinical Immunology, vol. 106, no. 3, pp. 197-200, 2003.

[25] K. Reich, G. Westphal, I. R. König et al., "Association of allergic contact dermatitis with a promoter polymorphism in the IL16 gene," Journal of Allergy and Clinical Immunology, vol. 112, no. 6, pp. 1191-1194, 2003.

[26] X.-L. Gan, Y.-H. Lin, Y. Zhang, T.-H. Yu, and L.-N. Hu, "Association of an interleukin-16 gene polymorphism with the risk and pain phenotype of endometriosis," DNA and Cell Biology, vol. 29, no. 11, pp. 663-667, 2010.

[27] K. M. Burkart, S. J. Barton, J. W. Holloway et al., "Association of asthma with a functional promoter polymorphism in the IL16 gene," Journal of Allergy and Clinical Immunology, vol. 117, no. 1, pp. 86-91, 2006.

[28] X. J. Gu, B. Cui, Z. F. Zhao et al., "Association of the interleukin (IL)-16 gene polymorphisms with Graves' disease," Clinical Immunology, vol. 127, no. 3, pp. 298-302, 2008.

[29] H. Xue, L. Gao, Y. Wu et al., "The IL-16 gene polymorphisms and the risk of the systemic lupus erythematosus," Clinica Chimica Acta, vol. 403, no. 1-2, pp. 223-225, 2009.

[30] Y. Chen, H. Huang, S. Liu et al., "IL-16 rsl1556218 gene polymorphism is associated with coronary artery disease in the Chinese Han population," Clinical Biochemistry, vol. 44, no. 13, pp. 1041-1044, 2011.

[31] J. Wu, Y. Wang, Y. Zhang, and L. Li, "Association between interleukin-16 polymorphisms and risk of coronary artery disease," DNA and Cell Biology, vol. 30, no. 5, pp. 305-308, 2011.

[32] H. P. Adams Jr., B. H. Bendixen, L. J. Kappelle et al., “Classification of subtype of acute ischemic stroke: definitions for use in a multicenter clinical trial. TOAST. Trial of org 10172 in acute stroke treatment," Stroke, vol. 24, no. 1, pp. 35-41, 1993.

[33] A. Molvarec, G. Széplaki, M. Kovács et al., "Estrogen receptor $\alpha$ (ESR1) PvuII and XbaI gene polymorphisms in ischemic stroke in a Hungarian population," Clinica Chimica Acta, vol. 382, no. 1-2, pp. 100-105, 2007.

[34] S. W. M. John, G. Weitzner, R. Rozen, and C. R. Scriver, "A rapid procedure for extracting genomic DNA from leukocytes," Nucleic Acids Research, vol. 19, no. 2, p. 408, 1991.

[35] L.-B. Gao, L. Rao, Y.-Y. Wang et al., "The association of interleukin-16 polymorphisms with IL-16 serum levels and risk of colorectal and gastric cancer," Carcinogenesis, vol. 30, no. 2, pp. 295-299, 2009.

[36] S. Laberge, O. Ghaffar, M. Boguniewicz, D. M. Center, D. Y. Leung, and Q. Hamid, "Association of increased CD4+Tcell infiltration with increased IL-16 gene expression in atopic dermatitis," Journal of Allergy and Clinical Immunology, vol. 102, no. 4, part 1, pp. 645-650, 1998.

[37] S. Lee, H. Kaneko, I. Sekigawa, Y. Tokano, Y. Takasaki, and H. Hashimoto, "Circulating interleukin-16 in systemic lupus erythematosus," British Journal of Rheumatology, vol. 37, no. 12, pp. 1334-1337, 1998.

[38] L. Zhang, Z. G. Zhang, R. L. Zhang, M. Lu, M. Krams, and M. Chopp, "Effects of a selective CD11b/CD18 antagonist and recombinant human tissue plasminogen activator treatment alone and in combination in a rat embolic model of stroke," Stroke, vol. 34, no. 7, pp. 1790-1795, 2003.

[39] R. L. Z. Rui Lan Zhang, M. Chopp, N. Jiang et al., "Antiintercellular adhesion molecule-1 antibody reduces ischemic cell damage after transient but not permanent middle cerebral artery occlusion in the Wistar rat," Stroke, vol. 26, no. 8, pp. 1438-1443, 1995.

[40] M. Folwaczny, J. Glas, H.-P. Török et al., "Prevalence of the 295 T-to-C promoter polymorphism of the interleukin (IL)-16 gene in periodontitis," Clinical and Experimental Immunology, vol. 142, no. 1, pp. 188-192, 2005. 
[41] V. H. Brait, T. V. Arumugam, G. R. Drummond, and C. G. Sobey, "Importance of T lymphocytes in brain injury, immunodeficiency, and recovery after cerebral ischemia," Journal of Cerebral Blood Flow and Metabolism, vol. 32, no. 4, pp. 598-611, 2012.

[42] C. Kleinschnitz, P. Kraft, A. Dreykluft et al., "Regulatory T cells are strong promoters of acute ischemic stroke in mice by inducing dysfunction of the cerebral microvasculature," Blood, vol. 121, no. 4, pp. 679-691, 2013. 


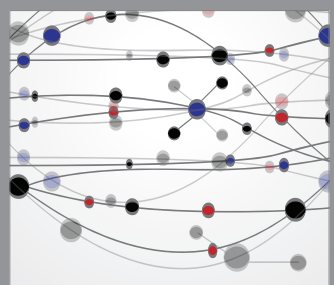

The Scientific World Journal
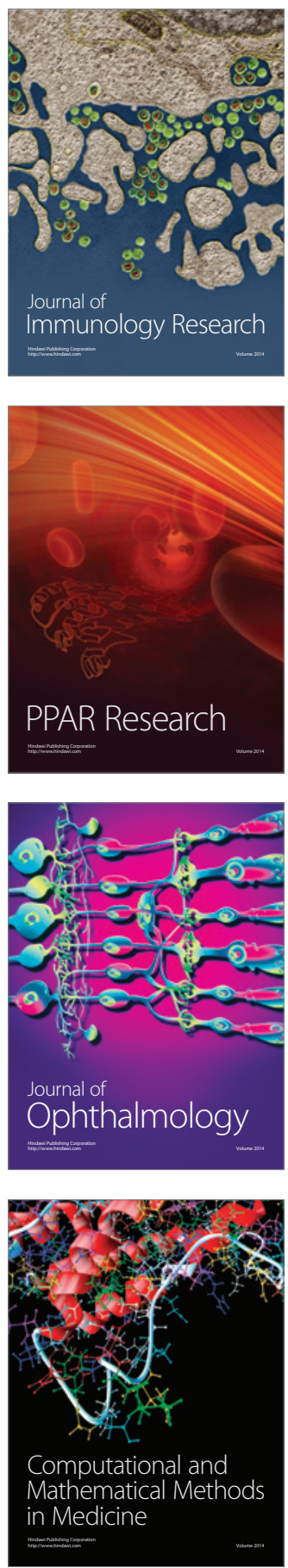

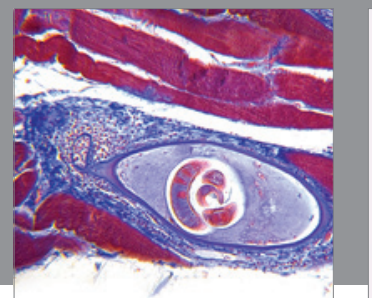

Gastroenterology

Research and Practice
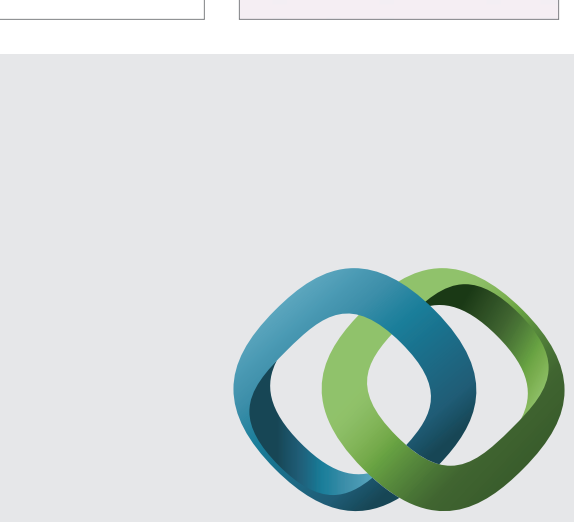

\section{Hindawi}

Submit your manuscripts at

http://www.hindawi.com
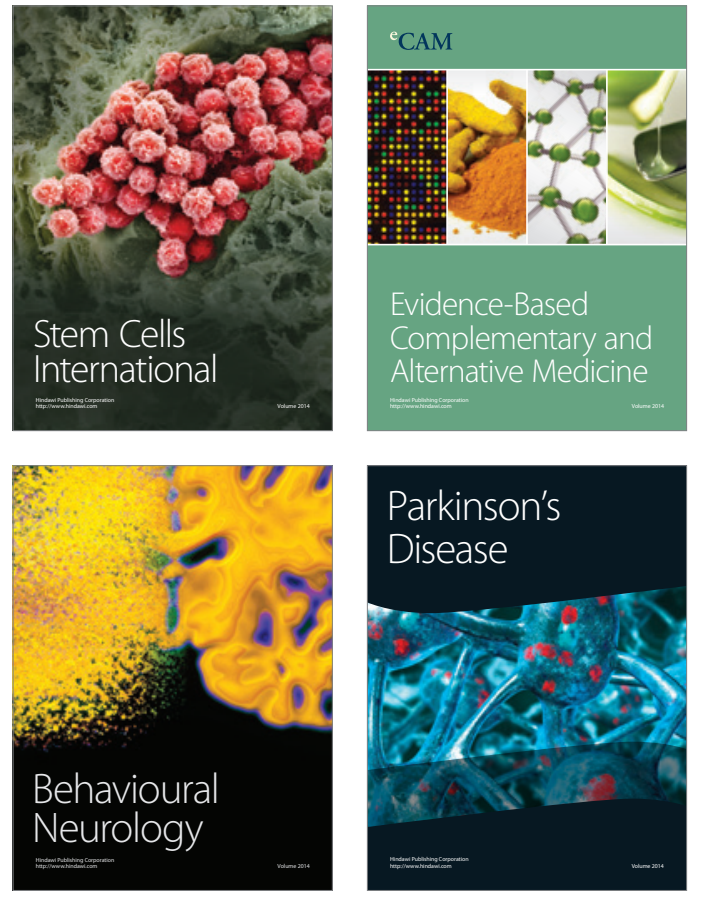
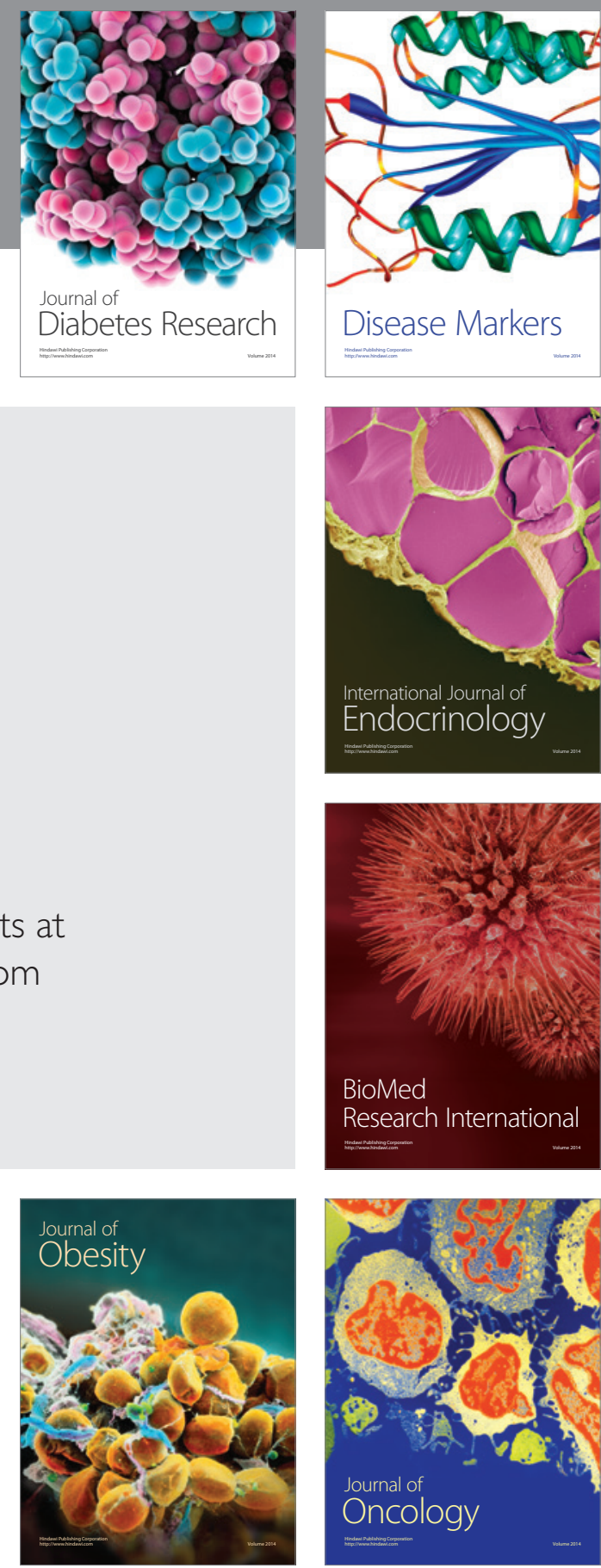

Disease Markers
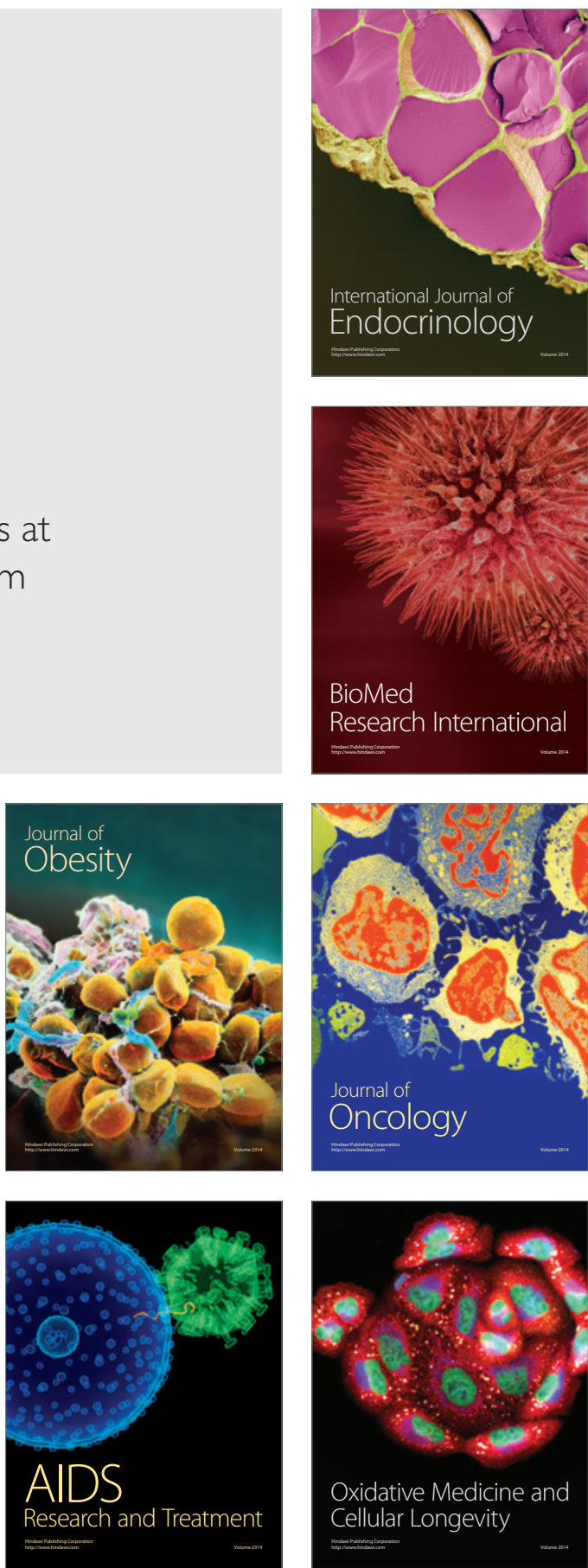